\title{
Motivation Differences between Youth Single-Sport, Multi-Sport, and Single-Sport Specialized Athletes in the Western United States
}

\author{
By Kyle L. Crouch ${ }^{*}$, Abigail Larson ${ }^{ \pm} \&$ Mark DeBeliso ${ }^{\bullet}$
}

\begin{abstract}
The motivation for youth sport involvement may differ for single-sport (nonspecialists), multi-sport, and single-sport specialized athletes. To investigate differences between adolescent single-sport athletes (NSSA), multi-sport athletes (MSA), and single-sport specialized athletes (SSSA) on measures of sport enjoyment and motivation. A secondary aim was to compare these variables between age groups. Adolescent sport participants in $6^{\text {th }}, 7^{\text {th }}$, and $8^{\text {th }}$ grade from the Western United States $(n=306$, age $=13.0 \pm 1.0$ yrs) completing the Sources of Enjoyment in Youth Sport Questionnaire (SEYSQ) that assesses sport enjoyment in the subscales of self-referenced competency (SRC), other-referenced competency and recognition (ORCR), effort expenditure (EE), competitive excitement $(C E)$, affiliation with peers $(A P)$, and positive parental involvement (PPI). The participants also reported their age, gender, grade, years of sport participation and sport status (NSSA, MSA, SSSA). SSSA reported significantly more enjoyment in all subscales except PPI when compared to NSSA ( $p<0.05$; ES 0.4-0.99). MSA and SSSA showed significant differences in the subscales of SRC and EE; however, effect size was small (0.37 and 0.33, respectively). Overall scores for intrinsic and extrinsic motivation were significantly lower among NSSA compared to MSA and SSSA $(p<0.01)$ with no differences between MSA and SSSA ( $p>0.05)$. Results revealed no significant differences in the SEYSQ's subscales for age ( $p>0.05)$. Within the parameters of this study, adolescents that specialize in a single sport or those who compete in multiple sport both rely on intrinsic and extrinsic sources of enjoyment for motivation in very similar ways; whereas adolescent NSSA are less motivated and experience less enjoyment from sport participation compared to MSA and SSSA.
\end{abstract}

Keywords: adolescent, enjoyment, SEYSQ, motivation, sport psychology

\section{Introduction}

The study of motivation is amongst the most predominant topics within sport psychology (Roberts 2001). Within athletics, most would agree that motivation is the foundation or the "heart" of sport performance and achievement (Duda and Treasure 2015). Because of the importance of motivation for optimal sport performance, continued study of the topic, particularly during developmental periods, is warranted. Clancy et al. (2017, p. 1) emphasize this need and state,

\footnotetext{
*Graduate Student, Department of Kinesiology and Outdoor Recreation, Southern Utah University, USA.

${ }^{ \pm}$Associate Professor, Department of Kinesiology and Outdoor Recreation, Southern Utah University, USA.

Professor, Department of Kinesiology and Outdoor Recreation, Southern Utah University, USA.
} 
"There is utility in studying motivation, as it provides a theoretical and practical insight into why one initiates, regulates, sustains, directs, and discontinues behavior". Ideally, those involved in youth sport development programs understand and utilize motivational techniques that enhance sport performance, enjoyment, and engagement. In turn, this creates situations that encourage an athlete to continue to participate in sport, reach feelings of competency, and perform to their highest abilities.

Current research suggests motivation levels, as well as specific motivators, vary among athletes. According to the Self-Determination Theory (Deci and Ryan 1985), the orientation of motivation is distinguished between intrinsic and extrinsic motivation (Ryan and Deci 2000). Intrinsic motivation refers to engaging in an activity because it is interesting, fulfilling, and enjoyable, while extrinsic motivation refers to external reasons for sport participation, such as receiving a reward or avoiding punishment (Rottensteiner et al. 2015). Previous research indicates intrinsic and extrinsic motivation are essential concepts for understanding sources of enjoyment and continued participation in athletics (Deci and Ryan 2002, Vallerand and and Rousseau 2001).

Throughout an athlete's sport experience, there is a need to balance intrinsic and extrinsic motivation (Sugarman 1999). Using extrinsic rewards to motivate a young athlete can bring short-term enjoyment and improve athletic performance but relying heavily on such dividends may be detrimental to intrinsic motivation. According to Hatch et al. (n.d.), "Extrinsically motivated athletes tend to focus on the competitive or performance outcome. An over-emphasis on extrinsic motivation may lead athletes to feel like their behavior is controlled by the extrinsic rewards." Thus, an excess of extrinsic rewards will draw athletes away from the enjoyment of sport activity. In addition, focusing on the performance outcomes can cause anxiety and loss of interest and value of achievement for an athlete (Hatch et al. n.d.). Furthermore, providing tangible rewards for engaging in an activity, completing an activity, or reaching a certain level of performance in an activity, may undermine intrinsic motivation, especially in school-aged children (Deci et al. 2001). However, the use of extrinsic methods of motivation that promote selfdetermined motivation, such as positive verbal feedback by a coach, positively impacts intrinsic motivation and feelings of competence (Vallerand and Reid 1988).

Enjoyment is considered a critical component of the competitive youth sport experience (Scanlan and Lewthwaite 1986), and an important aspect of intrinsic and extrinsic motivation. Research suggests sport enjoyment is correlated with motivation (Scanlan et al. 1989), engagement (Weiss and Chaumeton 1992), and continued involvement (Scanlan et al. 1993). The definition of sport enjoyment is widely accepted as "a positive affective response to the sport experience that reflects generalized feelings such as pleasure, liking, and fun" (Scanlan et al. 1993). This definition has its roots in an earlier study conducted by Scanlan and Lewthwaite (1986), which introduced the model of sport enjoyment. This model conceptualizes how enjoyment in sport experiences can come from several sources by combining achievement and nonachievement components with intrinsic and extrinsic elements (Wiersma 2001). Accordingly, enjoyment is not synonymous 
with intrinsic motivation. Although enjoyment is associated with intrinsic motivation, sources of enjoyment may also come from extrinsic aspects of training and competition (Scanlan and Lewthwaite 1986).

Determining the amount and sources of sport enjoyment experienced by an athlete also provides valuable information as to what motivates an individual to participate in sport. The Sources of Enjoyment in Youth Sport Questionnaire (SEYSQ) (Wiersma 2001) is a 28-item survey that quantifies sport enjoyment by, among other things, measuring the level of intrinsic and extrinsic motivation (Figure 1). Using the SEYSQ for data acquisition 526 adolescents, Ages 14-18, participated in a study conducted by Berki and Piko (2017). Their study's research indicates that "there are important differences according to age and gender in the sources of sport enjoyment" (Berki and Piko 2017, p. 230). Their results suggest a negative association between age and sources of sport enjoyment, meaning that sport enjoyment decreases with age. Between genders, boys scored higher in CE and ORCR subcategories, indicating that boys are more competitive than girls, whereas girls PPI as a higher source of enjoyment than boys. Other factors shown to affect sport enjoyment include coaching influences and the nature of the sport. A 2008 study by McCarthy, Jones, and Clark-Carter, assessed sources of enjoyment among 152 youth sport athletes, Ages 8-15, participating in different sport types (team sport and individual sport) using the SEYSQ. Participants who competed in basketball, football [soocer], netball, rounders, hockey, and rugby were classified as team-sport athletes, and those who competed in athletics, badminton, cricket, cycling, martial arts, swimming, tennis, and trampolining as individual-sport athletes. It is reported that participants in team sport had significantly greater self-referenced competency, affiliation with peers, competitive excitement, positive parental involvement, and enjoyment compared with individual sport participants and suggests:

Team sport for children in the sampling and specializing years of sport participation offer a unique blend of enjoyment sources that would benefit all children. Moreover, a team sport in addition to an individual sport may serve the needs of children in the sampling years before they enter the specializing years when they choose a sport to specialize in (McCarthy et al. 2008).

Research on the effects of other factors, such as specific type of sport played or number of sport in which an athlete participates, on sport enjoyment is limited. Those involved in youth sport development programs would benefit from additional research in this area of study. To this end, coaches and trainers need to understand the different motivators among specific populations of athletes. Additionally, coaches and trainers would benefit by understanding common sources of enjoyment and motivation among diverse athlete groups; however, little is known regarding the level of sport enjoyment and primary motivators to participate in sport in specific populations. For example, sport samplers may have different sources and degrees of enjoyment compared to sport specialists.

Specifically, in reference to sport specialists, previous research suggests early sport specialization may reduce intrinsic motivation (Wiersma 2000, Gould and Carson 2004, Côté et al. 2009). Athletic development occurs over the course of 
three stages: early years, middle years, late years (Bloom 1985). Each stage respectively plays a vital role in the development of an athlete. Desired athletic development starts with a focus on fun and passion for athletics through participation in multiple sport (early years), moves to skill progression for specific sport (middle years), and reaches technical skill expansion through extensive, deliberate practice for optimal performance in a single sport (late years) (Gould and Carson 2004). Gould and Carson (2004) maintain that the majority of champion-level athletes do not skip any of developmental stages in order to specialize early in a sport, and they assert that when stages are skipped in order to specialize early, it "usually has dire consequences, as elite performance is based on the development of proper fundamentals." Moreover, if the early-years stage that emphasizes fun and love of the activity is passed over for specialized practice and advanced training, the athlete may not develop an intrinsic desire and motivation for the sport. Other studies also show that the bulk of elite athletes surveyed participated in various sport (sampling) prior to single-sport specialization (Côté et al. 2009).

When using the SEYSQ, are there significant differences between singlesport athletes (NSSA), multi-sport athletes (MSA), and single-sport specialist athletes (SSSA), respectively, on measures of sport enjoyment and/or measures of intrinsic and extrinsic motivation? To the best of our knowledge, this study is the first to consider the relationship between sport status (NSSA, SSSA, or MSA) and sources of enjoyment in youth adolescent athletes. The findings from this study will help those involved in youth sport tailor motivational practices for specific athlete populations. Thus, influenced by the current trend of early sport specialization and outcomes of sport enjoyment and motivation, this study aims to quantify the amount and sources of sport enjoyment among adolescent athletes and assess differences between NSSA, MSA, and SSSA. A secondary purpose of this study is to describe any differences in sources of enjoyment and motivation between age groups (grades).

\section{Methods and Materials}

\section{Participants}

The Southern Utah University IRB committee (IRB APPROVAL \#24032021a) and a Utah school district approved this study prior to participant recruitment. Participants for this study represent a convenience sample which consisted of 306 athletes (190 male and 116 female athletes) separated by grades, $6^{\text {th }}$ (11-12 years), $7^{\text {th }}$ (12-13 years), and $8^{\text {th }}$ (13-14 years) within a Utah school district and compete in one or more organized sport. Participation was voluntary. The Southern Utah University IRB committee and county school district waived the requirement for parental permission and minor assent. The county school district and IRB committee permitted passive consent with the precondition that students and parents be provided a parental consent document that included potential benefits, adverse consequences, anonymity protection and data security, 
the ability for the student to withdraw at any time, researcher's contact information, and a way for the parent to see survey items. Information was disseminated to parents via handouts and email.

\section{Procedures}

A short presentation about the survey was given to students during physical education classes when the survey was distributed. Student-athletes who volunteered to participate were given a pencil and paper document that included the researcher-designed demographic questionnaire and the Sources of Enjoyment in Youth Sport Questionnaire (SEYSQ). The researcher briefly introduced the survey format and terms and answered any questions. Student participants were asked to complete the entire survey as honestly as possible. Upon completing all survey questions, students returned the paper document to the researcher. Participation in this study was voluntary, and data collected from the questionnaire was anonymous, untraceable, and analyzed in aggregate. No compensation was provided for participation.

\section{Instruments}

The demographics questionnaire included two sections. Section 1 contained four multiple-choice questions to assess age, gender, grade in school, and total years involved in organized sport. Section 2 contained questions regarding the athlete's status, sport played, and the amount of time spent in each respected sport over the past 12-month period. The athlete self-identified as either an NSSA (athlete that competes in a single organized sport), MSA (athlete that competes in more than one organized sport), or SSSA (athlete that specializes in a single organized sport dedicating eight or more months per year to the specific sport through games, practices, training, etc.) (Jayanthi et al. 2013). Each participant also identified his/her respective sport(s) and the number of months dedicated to each sport in the last calendar year. Time dedicated to each sport for multi-sport athletes had the potential of adding up to more than 12 months, as some sport seasons and training periods overlap.

The third and final portion of the survey was the SEYSQ, a 28-item questionnaire designed to quantitatively measure the sources of enjoyment in youth sport using a 5-point Likert Scale (1=not at all, 2=a little, 3=not sure, 4=yes, $5=$ very much) Wiersma (2001). The SEYSQ provides data that enables researchers to classify participants within extrinsic/intrinsic and achievement/ nonachievement continuums (Wiersma 2001). The 28-items scaled on the SEYSQ are distributed into a 6-factor model of sport enjoyment, including self-referenced competency (SRC), other-referenced competency and recognition (ORCR), effort expenditure (EE), competitive excitement (CE), affiliation with peers (AP), and positive parental involvement (PPI). Second-order factor structures realized through these six factors are extrinsic/intrinsic and achievement/nonachievement models. Factors that contribute to intrinsic motivation include SRC, CE, and EE subscales. Factors contributing to extrinsic motivation include ORCR, AP, and PPI subscales (see 
Figure 1). Achievement and nonachievement models were not explored in the present study.

Figure 1. Contributing Subcategories for Intrinsic and Extrinsic Motivation

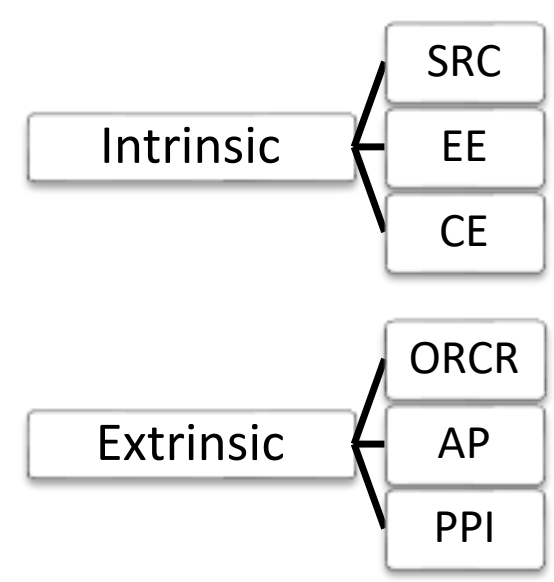

SRC: Self-Referenced Competency, CE: Competitive Excitement, EE: Effort Expenditure,

ORCR: Other Referenced Competency and Recognition, AP: Affiliation with Peers, PPI: Positive Parental Involvement

\section{Design and Analysis}

Survey data were checked for completeness, input into Microsoft Excel, and analyzed. Descriptive statistics for age, gender, grade, sport status, and the amount of time spent competing in sport over the previous 12-month period were calculated. Data were categorized by sport status: NSSA, MSA, and SSSA. Means and standard deviations were calculated for each of the 6 factors on the SEYSQ (SRC, CE, EE, ORCR, AP, and PPI) and compared between NSSA, MSA, and SSSA. Scores from corresponding subcategories were summed to yield an intrinsic and extrinsic motivation score, respectively, and means were compared between NSSA, MSA, and SSSA. Corresponding subcategories are classified according to Wiersma (2001), see Figure 1. Means and standard deviations for each of the previously listed variables were calculated and compared between all males and females, respectively, as well as between the 3 different grades, respectively. Comparisons between the 3 sport status groups were made using a single-factor ANOVA test. Post hoc analysis was conducted using the Scheffe Method. Independent two-sample t-tests were used for age and gender comparisons. Significance was set at $\mathrm{p} \leq 0.05$ for all. Effect size was calculated for all variables that showed significant differences and classified, as defined by Cohen (1988), as: small $\mathrm{d}=|0.2|$, medium $\mathrm{d}=|0.5|$, and large $\mathrm{d}=|0.8|$. 


\section{Results}

Participants in this study represented 34 sports, including baseball, basketball, football, soccer, dance, volleyball, cheerleading, etc. Demographic information regarding participant gender and grade is presented in Table 1. Participant gender, grade, and competitive sport status are shown in Table 2.

Table 1. Participant Gender and Grade

\begin{tabular}{|l|c|c|c|c|}
\hline \multicolumn{5}{|c|}{ GRADE } \\
\hline Male & $\mathbf{6}^{*}$ & $\mathbf{7}^{* *}$ & $\mathbf{8}^{* * *}$ & Total \\
\hline Female & 57 & 27 & 106 & 190 \\
\hline Total & 37 & 13 & 66 & 116 \\
\hline
\end{tabular}

*mean age 11.8 years; standard deviation \pm 0.5

** mean age 12.7 years; standard deviation \pm 0.5

$* * *$ mean age 13.6 years; standard deviation \pm 0.5

Table 2. Participant Sport Status by Gender and Grade

\begin{tabular}{|c|c|c|c|c|}
\hline \multicolumn{5}{|c|}{ Male $(n=190)$} \\
\hline Sport Status & \multicolumn{3}{|c|}{ Grade } & \multirow[b]{2}{*}{ Totals } \\
\hline & $6^{*}$ & $7 * *$ & $\mathbf{8}^{* * * *}$ & \\
\hline NSSA & 6 & 3 & 16 & 25 \\
\hline MSA & 40 & 18 & 55 & 113 \\
\hline SSSA & 11 & 6 & 35 & 52 \\
\hline Total & 57 & 27 & 106 & 190 \\
\hline \multicolumn{5}{|c|}{ Female $(n=116)$} \\
\hline & $6^{*}$ & $7 * *$ & $\mathbf{8}^{* * * *}$ & Totals \\
\hline NSSA & 6 & 2 & 9 & 17 \\
\hline MSA & 16 & 7 & 22 & 45 \\
\hline SSSA & 15 & 4 & 35 & 54 \\
\hline Total & 37 & 13 & 66 & 116 \\
\hline
\end{tabular}

Descriptive statistics (means and standard deviations) for each subcategory of the SEYSQ are presented in Table 3. Higher scores indicate a greater source of enjoyment. The highest possible scores vary between categories and are as follows: SRC, CE, and PPI 20 points each, EE and AP 25 points each, and ORCR 30 points (Table 3). Subcategories were grouped into intrinsic and extrinsic categories, respectively, and summed for a total intrinsic and extrinsic score (Table 3).

Significant differences $(\mathrm{p}<0.05)$ between sport groups were found for all of the SEYSQ subcategories except for PPI (Table 3). Post-hoc testing using the Scheffe Method was used to determine where these differences were between each of the respected sport status groups (Table 4). NSSA scored significantly lower on several measures of enjoyment and overall intrinsic and extrinsic enjoyment, respectively, compared to MSA and SSSA (Tables 3 and 4). MSA and SSSA differed significantly on measures SRC and EE, both associated with intrinsic motivation, 
but total intrinsic and extrinsic motivation scores, respectively, did not differ between MSA and SSSA (Table 3 and 4).

Table 3. NSSA, MSA, and SSSA Comparison within the SEYSQ Subcategories

\begin{tabular}{|c|c|c|c|c|}
\hline \multicolumn{5}{|c|}{ Intrinsic Categories } \\
\hline & SRC & $\mathrm{CE}$ & $\mathrm{EE}$ & Overall Scores \\
\hline & $\begin{array}{l}\text { (highest score } \\
\text { possible }=20 \text { ) }\end{array}$ & $\begin{array}{l}\text { (highest score } \\
\text { possible }=20 \text { ) }\end{array}$ & $\begin{array}{l}\text { (highest score } \\
\text { possible }=25 \text { ) }\end{array}$ & $\begin{array}{l}\text { (highest score } \\
\text { possible }=65 \text { ) }\end{array}$ \\
\hline $\begin{array}{l}\text { NSSA } \\
(\mathrm{n}=42)\end{array}$ & $16.9+/-2.2$ & $16.1+/-2.7^{*}$ & $19.1+/-3.6^{*}$ & $52.0+/-7.0^{*}$ \\
\hline $\begin{array}{l}\text { MSA } \\
(n=158)\end{array}$ & $17.5+/-2.2 * *$ & $17.9+/-2.1$ & $21.3+/-3.0 * *$ & $56.7+/-6.1$ \\
\hline $\begin{array}{l}\operatorname{SSSA}(\mathrm{n}= \\
106)\end{array}$ & $18.3+/-1.8^{* * *}$ & $17.9+/-2.5^{* * *}$ & $22.2+/-2.7 * * *$ & $58.4+/-5.5^{* * *}$ \\
\hline & $P$-value $=0.00$ & $P$-value $=0.00$ & $P$-value $=0.00$ & $P$-value $=0.00$ \\
\hline \multicolumn{5}{|c|}{ Extrinsic Categories } \\
\hline & ORCR & AP & PPI & Overall Scores \\
\hline & $\begin{array}{l}\text { (highest score } \\
\text { possible }=30 \text { ) }\end{array}$ & $\begin{array}{l}\text { (highest score } \\
\text { possible= } 25 \text { ) }\end{array}$ & $\begin{array}{l}\text { (highest score } \\
\text { possible= } 20 \text { ) }\end{array}$ & $\begin{array}{l}\text { (highest score } \\
\text { possible }=75 \text { ) }\end{array}$ \\
\hline $\begin{array}{l}\text { NSSA } \\
(\mathrm{n}=42)\end{array}$ & $19.6+/-5.4^{*}$ & $19.9+/-4.4$ & $16.4+/-3.7$ & $55.9+/-10.6^{*}$ \\
\hline $\begin{array}{l}\text { MSA } \\
(n=158)\end{array}$ & $23.4+/-4.8$ & $21.1+/-3.0$ & $16.6+/-3.5$ & $61.1+/-8.5$ \\
\hline \multirow[t]{2}{*}{$\begin{array}{l}\operatorname{SSSA}(n= \\
106)\end{array}$} & $23.1+/-5.4 * * *$ & $21.4+/-3.3 * * *$ & $17.1+/-3.2$ & $61.6+/-9.5 * * *$ \\
\hline & $P$-value $=0.00$ & $P$-value $=0.04$ & $P$-value $=0.35$ & $P$-value $=0.00$ \\
\hline
\end{tabular}

SRC: Self-Referenced Competency, CE: Competitive Excitement, EE: Effort Expenditure

ORCR: Other Referenced Competency and Recognition, AP: Affiliation with Peers, PPI: Positive Parental Involvement

significant difference $\mathrm{p}<0.05$

* significant difference found between NSSA and MSA

*** significant difference found between MSA and SSSA

*** significant difference found between NSSA and SSSA

Table 4. Effect Size for Significant Differences between NSSA, MSA, and SSSA within the SEYSQ Subcategories

\begin{tabular}{|c|c|c|c|c|c|c|c|c|c|}
\hline \multirow{2}{*}{\multicolumn{2}{|c|}{$\begin{array}{l}\text { Pairwise } \\
\text { Comparison }\end{array}$}} & \multicolumn{8}{|c|}{ Effect Size } \\
\hline & & \multirow{2}{*}{$\begin{array}{l}\text { SRC } \\
\text { NSD }\end{array}$} & \multirow{2}{*}{$\frac{\mathrm{CE}}{0.77^{* *}}$} & \multirow{2}{*}{$\frac{\mathrm{EE}}{0.67 * *}$} & \multirow{2}{*}{$\begin{array}{l}\text { ORCR } \\
0.74 * *\end{array}$} & \multirow{2}{*}{$\frac{\mathrm{AP}}{\mathrm{NSD}}$} & \multirow{2}{*}{$\frac{\text { PPI }}{\text { NSD }}$} & \multirow{2}{*}{$\begin{array}{c}\text { Intrinsic } \\
\text { Overall } \\
0.71^{* *}\end{array}$} & \multirow{2}{*}{$\begin{array}{c}\begin{array}{c}\text { Extrinsi } \\
\text { Overall }\end{array} \\
0.54^{* *}\end{array}$} \\
\hline NSSA & MSA & & & & & & & & \\
\hline MSA & SSSA & $0.37 *$ & NSD & $0.32 *$ & NSD & NSD & NSD & NSD & NSD \\
\hline NSSA & SSSA & $0.62 * *$ & $0.73 * *$ & $0.99 * * *$ & $0.64 * *$ & $0.4^{*}$ & NSD & $1.0 * * *$ & $0.57 * *$ \\
\hline
\end{tabular}

SRC: Self-Referenced Competency, CE: Competitive Excitement, EE: Effort Expenditure

ORCR: Other Referenced Competency and Recognition, AP: Affiliation with Peers

NSSA: Single-sport Athlete; MSA: Multi-sport Athlete; SSSA: Single-sport Specialized Athlete

$\mathrm{NSD}=$ No significant difference

* 'small' effect size

** 'medium' effect size

*** 'large' effect size

Except for PPI, no significant differences in sources of enjoyment scores or measures of intrinsic or extrinsic motivation were found between age groups (see Table 5). Comparisons between the 3 grades were made using a single-factor ANOVA test. Post hoc analysis was conducted using the Scheffe Method finding 
that there was a statistically significant difference between $6^{\text {th }}$ and $7^{\text {th }}$ grade athletes and $7^{\text {th }}$ and $8^{\text {th }}$ grade athletes, but not between $6^{\text {th }}$ and $8^{\text {th }}$ grade athletes (see Table 6). Effect size was calculated for all variables that showed meaningful differences and classified, as defined by Cohen (1988), as: small $\mathrm{d}=|0.2|$, medium $\mathrm{d}=|0.5|$, and large $\mathrm{d}=|0.8|$. It should be noted that while PPI was significantly lower for 7 graders compared to $6^{\text {th }}$ and $8^{\text {th }}$ graders, the Overall Extrinsic score was still statistically similar for all grades $(\mathrm{p}>0.05)$.

Table 5. Grade Comparison within the SEYSQ Subcategories

\begin{tabular}{|c|c|c|c|c|}
\hline \multicolumn{5}{|c|}{ Intrinsic Categories } \\
\hline & SRC & $\mathrm{CE}$ & $\mathrm{EE}$ & Overall Scores \\
\hline & $\begin{array}{l}\text { (highest score } \\
\text { possible }=20 \text { ) }\end{array}$ & $\begin{array}{l}\text { (highest score } \\
\text { possible }=20 \text { ) }\end{array}$ & $\begin{array}{l}\text { (highest score } \\
\text { possible }=25 \text { ) }\end{array}$ & $\begin{array}{c}\text { (highest score possible }= \\
65)\end{array}$ \\
\hline 6 th grade $(n=94)$ & $17.7+/-2.3$ & $17.8+/-2.4$ & $21.1+/-3.0$ & $56.7+/-6.6$ \\
\hline $7^{\text {th }}$ grade $(n=40)$ & $17.4+/-2.2$ & $18.0+/-2.2$ & $20.5+/-3.3$ & $55.8+/-5.8$ \\
\hline 8 th grade $(n=172)$ & $17.7+/-2.0$ & $17.5+/-2.5$ & $21.6+/-3.2$ & $56.8+/-6.3$ \\
\hline & $P$-value $>0.05$ & $P$-value $>0.05$ & $P$-value $>0.05$ & $P$-value $>0.05$ \\
\hline \multicolumn{5}{|c|}{ Extrinsic Categories } \\
\hline & ORCR & $\mathrm{AP}$ & PPI & Overall Scores \\
\hline & $\begin{array}{l}\text { (highest score } \\
\text { possible }=30 \text { ) }\end{array}$ & $\begin{array}{l}\text { (highest score } \\
\text { possible }=25 \text { ) }\end{array}$ & $\begin{array}{l}\text { (highest score } \\
\text { possible }=20 \text { ) }\end{array}$ & $\begin{array}{c}\text { (highest score possible }= \\
75)\end{array}$ \\
\hline 6 th grade $(n=94)$ & $23.1+/-5.2$ & $21.0+/-3.3$ & $17.2+/-3.2$ & $61.3+/-9.1$ \\
\hline $7^{\text {th }}$ grade $(n=40)$ & $22.9+/-5.1$ & $20.6+/-3.2$ & $15.3+/-3.9$ & $58.8+/-9.8$ \\
\hline \multirow[t]{2}{*}{8 th grade $(n=172)$} & $22.6+/-5.2$ & $21.1+/-3.4$ & $16.8+/-3.3$ & $60.5+/-9.3$ \\
\hline & $P$-value $>0.05$ & $P$-value $>0.05$ & $P$-value $=0.01 *$ & $P$-value $>0.05$ \\
\hline
\end{tabular}

SRC: Self-Referenced Competency, CE: Competitive Excitement, EE: Effort Expenditure

ORCR: Other Referenced Competency and Recognition, AP: Affiliation with Peers, PPI: Positive Parental Involvement

*Significant differences found between $6^{\text {th }}$ and $7^{\text {th }}$ grade and $7^{\text {th }}$ and $8^{\text {th }}$ grade

Table 6. Effect Size for Significant Differences between 6th, 7th, and $8^{\text {th }}$ Grades within the SEYSQ Subcategories

\begin{tabular}{|c|c|c|c|c|c|c|c|c|c|}
\hline \multirow{2}{*}{\multicolumn{2}{|c|}{$\begin{array}{c}\text { Pairwise } \\
\text { Comparison }\end{array}$}} & \multicolumn{8}{|c|}{ Effect Size } \\
\hline & & & & & & & & Intrinsic & Extrinsic \\
\hline $6^{\text {th }}$ grade & 7 th grade & NMD & NMD & NMD & NMD & NMD & $0.54 * *$ & NMD & NMD \\
\hline $6^{\text {th }}$ grade & $8^{\text {th }}$ grade & NMD & NMD & NMD & NMD & NMD & NMD & NMD & NMD \\
\hline $7^{\text {th }}$ grade & $8^{\text {th }}$ grade & NMD & NMD & NMD & NMD & NMD & $0.41 * *$ & NMD & NMD \\
\hline
\end{tabular}

SRC: Self-Referenced Competency, CE: Competitive Excitement, EE: Effort Expenditure

ORCR: Other Referenced Competency and Recognition, AP: Affiliation with Peers

NSSA: Single-sport Athlete; MSA: Multi-sport Athlete; SSSA: Single-sport Specialized Athlete

$\mathrm{NSD}=$ No meaningful difference

* 'small' effect size

** 'medium' effect size

$* * *$ 'large' effect size

\section{Discussion}

This study aimed to quantify the amount and sources of sport enjoyment, using the SEYSQ, among adolescent athletes and assess differences between NSSA, MSA, and SSSA as well as age groups. Results (total SEYSQ scores and subscale scores) indicated significant differences between NSSA and MSA/SSSA on several measures of sport enjoyment. MSA and SSSA both rely on intrinsic and 
extrinsic sources of enjoyment for motivation in very similar ways; whereas NSSA are less motivated and experience less enjoyment from sport compared to MSA and SSSA.

There were no significant differences in total SEYSQ score between the youngest grade $\left(6^{\text {th }}\right.$ grade; mean age $=11.8$; standard deviation \pm 0.5 years $)$ and oldest grade ( $8^{\text {th }}$ grade; mean age $=13.6$; standard deviation \pm 0.5 years $)$ of athletes who participated in this study. Previous studies have suggested that sport engagement and enjoyment decrease as age increases among youth athletes (McCarthy et al. 2008, Berki and Piko 2017). However, the current study showed no significant difference between younger and older participants in terms of enjoyment.

McCarthy and Jones (2007) reported the significance of sport enjoyment to children in the sampling years (ages 7-12). Their findings point out that children experience sport enjoyment from intrinsic and extrinsic sources (McCarthy and Jones 2007). Similarly, this current study's findings show that youth athletes (ages 11-14 years) experience enjoyment from both intrinsic and extrinsic sources regardless of identifying as an NSSA, MSA, or SSSA. The present study expands on previous youth sport motivation research by exploring the differences in sport enjoyment between adolescent NSSA, MSA, and SSSA. In addition, this study also examines differences between younger and older adolescent athletes as well as males and females on measures of sport enjoyment and sources of sport enjoyment. Coaches of athletes in this age group may manage a mix of NSSA, MSA, and SSSA that often compete on the same teams or in the same leagues. The results from the current study show that NSSA scored lower in many of the SEYSQ subcategories compared to MSA and SSSA. More specifically, NSSA scored lower than SSSA in all subcategories except for PPI. Furthermore, NSSA had lower means scores than MSA and SSSA across all subcategories showing significant differences in the subcategories of EE, CE, and ORCR, respectively, when compared to both groups.

Based on the findings from the present study, coaches working with NSSA should strive to meet the psychological needs of their athletes and create an atmosphere that promotes self-determined motivation. Self-determined motivation can be met if the psychological needs of autonomy, competence, and relatedness are satisfied (Deci and Ryan 1991). Time devoted to sport participation may also be a factor. NSSA may be lower in the SEYSQ subcategories because less time is spent participating in sport than MSA and SSSA; thus, they do not associate as much enjoyment with sport compared to the other groups.

Parents, coaches, and trainers can influence motivation through interactional behavior with their athletes (Mageau and Vallerand 2003). Pensgaard and Roberts (2002) affirm that coaches have an essential role in creating a motivational climate for their athletes that promotes an atmosphere of mastery rather than performance outcomes and found that even elite athletes emphasize the role of the coach as "important in that he or she is supportive and builds confidence." Parents, coaches, and trainers of youth athletes can emphasize intrinsic motivation by creating a task-oriented climate ("encourages participants to perform an activity in order to improve their skills" (Vallerand 2007)) as opposed to an ego-involved climate 
("leads athletes to believe they must outperform other athletes, including teammates" (Vallerand 2007)). Focusing on fun and challenging tasks can allow athletes to perform an activity for intrinsic reasons that may lead to more engaged action towards skill development, continued engagement in the sport, and increased enjoyment.

The results of this study are important for understanding the sources of enjoyment that impact intrinsic and extrinsic motivation in young NSSA, MSA, and SSSA; however, limitations exist. Participants in this study were all from the same geographical region (Western United States) and thus were exposed to sport through similar developmental sport programs. Consequently, the majority of the participants likely have similar sport backgrounds, limiting the study's external validity. The study was based on a convenience sample of student athletes. With that said, a limitation to the study is that not all age groups contain the same sample size.

\section{Conclusion}

The results of this study provide helpful information for those involved in youth sport development. Coaches need to focus on individual motivational needs to ensure all athletes experience improved competence and enjoyment. Specifically, implications of the results of this study suggest that to fit the needs of all the types of athletes and improve coaching, those involved in youth sport development programs should incorporate what already motivates these athletes into creating an environment that promotes excitement (CE) and focuses on the athlete or team performance rather than outcomes (SRC). Coaches, parents, and trainers of MSA and SSSA athletes should emphasize their hard work during practice, training, and competition (EE) and provide them with challenging tasks.

Future research in this area of study should include a more diverse geographical, ethnic, and socioeconomic sample of youth athletes. Research should also aim to examine how ability, number of years competing, and individual expectations affect the amount and sources of enjoyment in sport.

\section{References}

Berki T, Piko BF (2017) Hungarian adaptation and psychological correlates of sources of enjoyment in youth questionnaire among high school students. Cognition, Brain, Behavior. An Interdisciplinary Journal 21(4): 215-235.

Bloom B (1985) Developing talent in young people. NY: Ballantine Books.

Clancy R, Herring M, Campebell M (2017) Motivation measures in sport: a critical review and bibliometric analysis. Frontiers in Psychology.

Cohen J (1988) Statistical power analysis for the behavioral sciences. Hillsdale, NJ: Lawerence Erlbaum Associates.

Côté J, Lidor R, Hackfort D (2009) ISSP position stand: to sample or to specialize? Seven postulates about youth sport activities that lead to continued participation and elite performance. International Journal of Sport \& Exercise Psychology 7(1): 7-17. 
Deci E, Ryan R (1985) Intrinsic motivation and self-determination in human behavior. New York: Plenum.

Deci E, Ryan R (1991) A motivational approach to self: integration in personality. In R Deinstber (ed.), Nebraska Symposium on Motivation, volume 38: Perspectives on motivation, 237-288. Lincoln, NE: University of Nebraska Press.

Deci E, Ryan R (2002) Handbook of self-determination research. Rochester, NY: University of Rochester Press.

Deci E, Koestner R, Ryan R (2001) Extrinsic rewards and intrinsic motivation in education: reconsidered once again. Review of Educational Research 7(1): 1-27.

Duda JL, Treasure DC (2015) The motivational climate, athlete motivation, and implications for quality of sport engagement. In JM Williams, V Krane (eds.), Applied Sport Psychology: Personal Growth to Peak Performance, 57-77. New York: McGraw-Hill education.

Gould D, Carson S (2004) Fun and games? Myths surrounding the role of youth sport in developing Olympic champions. Youth Studies Australia 23(1): 19-26.

Hatch S, Thomsen D, Waldron JJ (n.d.) Extrinsic rewards and motivation. Association for Applied Sport Psychology. Available at: https://appliedsportpsych.org/resources/re sources-for-coaches/extrinsic-rewards-and-motivation/.

Jayanthi N, Pinkham C, Dugas L, Patrick B, LaBella C (2013) Sport specialization in young athletes: evidence-based recommendations. Sport Health: A Multidisciplinary Approach 5(3): 251-257.

Mageau G, Vallerand R (2003) The coach-athlete relationship: a motivational model. Journal of Sport Sciences 21(11): 883-904.

McCarthy PJ, Jones MV (2007) A qualitative study of sport enjoyment in the sampling years. The Sport Psychologist 21(Dec): 400-416.

McCarthy P, Jones M, Clark-David D (2008) Understanding enjoyment in youth sport: a developmental perspective. Psychology of Sport and Exercise 9(2): 142-156.

Pensgaard A, Roberts C (2002) Elite athletes' experiences of motivational climate: the coach matters. Scandinavian Journal of Medicine and Science in Sport 12(1): 54-59.

Roberts GC (2001) Advances in motivation in sport and exercise. Champaign, Ill.: Human Kinetics.

Rottensteiner, C., Tolvanen, A., Laakso, L., \& Konttinen, N. (2015). Youth athletes' motivation, perceived competence, and persistence in organized team sport. Journal of Sport Behavior 38(4): 432-449.

Ryan RM, Deci EL (2000) Intrinsic and extrinsic motivation: classic definitions and new directions. Contemporary Educational Psychology, 54-67.

Scanlan TK, Lewthwaite R (1986) Social psychological aspects of competition for male youth participants: IV. predictors of enjoyment. Journal of Sport Psychology, 25-35.

Scanlan TK, Carpenter PJ, Lobel M, Simons JP (1993) Sources of enjoyment for youth athletes. Pediatric Exercise Science 5(3): 275-285.

Scanlan T, Stein G, Ravizza K (1989) An in-depth study of former elite figure skaters: II. sources of enjoyment. Journal of Sport \& Exercise 11(1): 65-83.

Sugarman K (1999) Winning the mental way: a practical guide to team building and mental training. Step Up Pub.

Vallerand R (2007) Intrinsic and extrinsic motivation in sport and physical activity: a review and a look at the future. In G Tenenbaum, R Eklund (eds.), Handbook of Sport Psychology, 59-83. Hoboken, N.J.: John Wiley and Sons, Inc.

Vallerand R, Reid G (1988) On the relative effects of positive and negative verbal feedback on males' and females' intrinsic motivation. Canadian Journal of Behavioural Science 20(3): 239-250. 
Vallerand R, Rousseau F (2001) Intrinsic and extrinsic motivation in sport and exercise: a review using the hierarchy model of intrinsic and extrinsic motivation. In R Singer, $\mathrm{H}$ Hausenblas, C Janelle (eds.), Handbook of Sport Psychology, 2nd Edition, 389-416. New York: John Wiley \& Sons.

Weiss M, Chaumeton N (1992) Motivational orientations in sport. In T Horn (ed.), Advances in Sport Psychology, 61-99. Champaign, IL: Human Kinetics.

Wiersma LD (2000) Risks and benefits of youth sport specialization: perspectives and recommendations. Pediatric Exercise Science 12(1): 13-22.

Wiersma LD (2001) Conceptualization and development of the sources of enjoyment in youth sport questionnaire. Measurements in Physical Education and Exercise Science 5(3): 153-177. 
